\title{
Microarchitectural changes during development of the cerebellar cortex
}

\author{
MIRIAM MECHA ${ }^{1}$, ANGEL L. PEÑA-MELIÁN² and MARIA J. BLANCO*,3 \\ ${ }^{1}$ Dpto. de Neurobiología Funcional y de Sistemas, Instituto Cajal, CSIC, ${ }^{2}$ Dpto. Anatomía y Embriología \\ Humana I. Facultad de Medicina, Universidad Complutense de Madrid, ${ }^{3}$ Dpto. de Ciencias Morfológicas, \\ Fisiología y Biomedicina, Facultad de Ciencias de la Salud, Universidad Europea de Madrid, Madrid, Spain
}

\begin{abstract}
The cerebellum is a highly conserved structure in the Central Nervous System (CNS) of vertebrates, and is involved in the coordination of voluntary motor behaviour. Supporting this function, the cerebellar cortex presents a layered structure which requires a precise spatial and temporal coordination of proliferation, migration and differentiation events. One of the characteristics of the developing cortex is the formation of the external granule cell layer (EGL) in the outermost part. The EGL is a highly proliferative transient layer which disappears when cells migrate inwards to form the inner granule cell layer. The balance between proliferation and migration leads to changes in EGL thickness, and might be related to "indentations" observed in the surface of the developing chick cerebellum. We have extended the observation of this feature to quail and mouse, supporting the idea that this phenomenon forms part of the mechanisms of cerebellar morphogenesis. Different factors involved in both mitotic activity and migration were analyzed in this study. Our results indicate that proliferation, more than formation of raphes for cell migration, is involved in the formation of indentations in the EGL. In addition, we show that vessels penetrating from the pial surface divide the EGL into regular regions at the time of the appearance of bulges and furrows. We conclude that indentations are the result of a coincidence in time of both the increase in thickness of the EGL and the establishment of the embryonic vascular pattern, which confers a characteristic transitory morphology to the surface of folia.
\end{abstract}
KEYWORDS: EGL, raphes, indentation, radial glia, vascularization, Purkinje cell, Sonic hedgehog, mouse, chick, quail

\section{Introduction}

The cerebellum is a part of the CNS very well conserved within the vertebrates. Several evidences from the neuroanatomy, electrophysiology and from the gene expression studies, as well as from knockout phenotypes, demonstrate that the cerebellum is a highly organized structure, with a remarkably somatotopy in the medial-lateral and rostro-caudal axes, necessary for its functional role in integration of sensory perception and the coordination of voluntary movements.

During cerebellar development, the cortex is formed by several layers: the external granule cell layer (EGL), the molecular layer formed by axons and fibers (ML), and the deepest one, the inner cortical cell layer (ICCL, according to Feirabend, 1990), formed by both mature granule cells and Purkinje cells. The ICCL would be the adult internal granular layer (IGL).
The EGL is formed by the granule cells that arise from the rhombic lip and migrate anteriorly over the surface of the developing cerebellar anlage, while the ventricular neuroepithelium of the fourth ventricle is the origin of Purkinje cell precursors (neuroblasts) that migrate along the Bergmann glial fiber system to populate the intermediate layer along DV axis to form the ICCL (Altman and Bayer, 1996).

The EGL is composed of actively dividing granule neuroblasts and constitutes an external proliferative layer (EGL), what represents a unique characteristic within the developing CNS. Mitotic activity of the EGL is a transient event that occurs between days 8-15 $(\mathrm{HH} 34-\mathrm{HH} 41)$ of chick embryonic development (Hanaway,

Abbreviations used in this paper: EGL, external granule cell layer; ICCL, inner cortical cell layer; IGL, internal granule layer; ML, molecular layer.

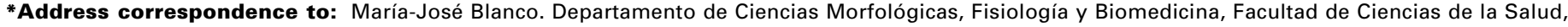

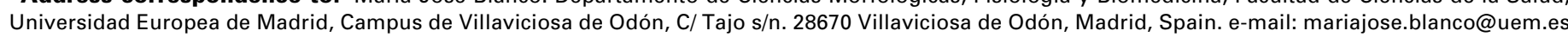


1967) and during the first postnatal week in the mouse (Smeyne and Goldowitz, 1989). During this period, a portion of the granule neuroblasts exits the cell cycle and accumulates forming the innermost substratum (iEGL) of the EGL. These cells are fusiform and oriented transversely to the AP axis, in contrast to the densely packed rounded cells of the outermost external layer (oEGL). The $E G L$ is then composed of two histologically well defined substrata. After this period, postmitotic cells migrate radially, along the fibers of Bergmann glial cells, passing through the molecular layer to form the definitive granule cell layer in the adult cerebellum, situated underneath the Purkinje cells (Feirabend, 1990; Altman and Bayer, 1996).

During development, the cerebellum undergoes a series of morphological changes in which massive growth, associated to the proliferation of the EGL, leads to intense cortical increase in thickness and folia formation. Concomitant with these transformations, Feirabend (1990) observed the presence of histologically evident interrumptions, with the apparience of teeth-like formations that bulge affecting the outermost stratum of the EGL. The so called indentations can be observed in the surface of folia onward day 12 of chick development and it was suggested to be related to formation of fissures (Feirabend, 1990).

An interesting point is that indentations are transitory and externally evident at $\mathrm{HH} 39-\mathrm{HH} 40$, a period related to both the greatest thickness of the EGL and the formation of the so-called "granule cell raphes". These are parasagittal ribbons of migrating cells from the EGL into the IGL, observed both in chicken and mouse (Luckner et al. 2001). Extensive proliferation of the EGL and subsequent migration of postmitotic differentiating granule neural cells results in massive growth of the cerebellum (Hatten and Heintz, 1995). Then, the cerebellar shape is transformed from its embryonic flat, oval form, to a more complex structure with deep fissures and large folia, what requires a precise spatial and temporal coordination of events as cell proliferation, differentiation and migration.

Much of the understanding about the mechanisms regulating the rapid expansion of granule progenitors has come from the analysis of mutations and experimental perturbations. In particular, Purkinje cells (PCs) play a critical role in the proliferative activity of granule cell progenitors (GCPs), since in mouse lacking PCs such as Lurcher and Staggerer, the GCP population is diminished (Herrup, 1983). In addition, when cerebellar PCs were ablated by the specific expression of diphtheria toxin, the most obvious early effect was a dramatically decrease in thickness of the overlying EGL (Smeyne et al. 1995). Depletion of Purkinje cells has been related to a reduction in the size of granule cell population due to a diminished mitotic activity. The mitotic activity of PCs is mediated by the expression of the secreted ligand Sonic hedgehog (Shh) in these cells, while granule cells express the Shh receptor Patched1 (Ptc1) (Smeyne et al. 1995). Shh is a potent inducer of granule cell proliferation (Wallace, 1999; Wechsler-Reya and Scott, 1999) as evidenced by the induction of cerebellar tumours (medulloblastoma) after the anomalous activation of the Sonic hedgehog/Patched signaling pathway in both mice and humans (Goodrich et al. 1997).

In addition of PCs influence, other factors might be related to the proliferative activity of the EGL. It has long been assumed that in both the adult and embryonic brain (germinal zones), neurogenesis and angiogenesis are closely linked (Wurmser et al. 2004). As it was described for the brain, the vascular system of the cerebellum is derived from the perivascular plexus that covers the neural tube. The overall process starts with the formation of small tortuous vessels in connection with each other on the surface of the cerebellar plate, later developing into perpendicularly penetrating vessels derived from the pial ones. When the EGL is proliferating, these vessels are sparse in number if compared to the pial vascular niche. Related to their trajectory, the initially linear vessels become arborized when they reach the $\mathrm{PC}$ layer forming a network connecting to the plexus situated in the deep cerebellar nucleus (Conradi et al. 1980; Yoshida etal. 1985). At the time the EGL has almost disappeared, the number of capillars increased in the molecular layer, forming
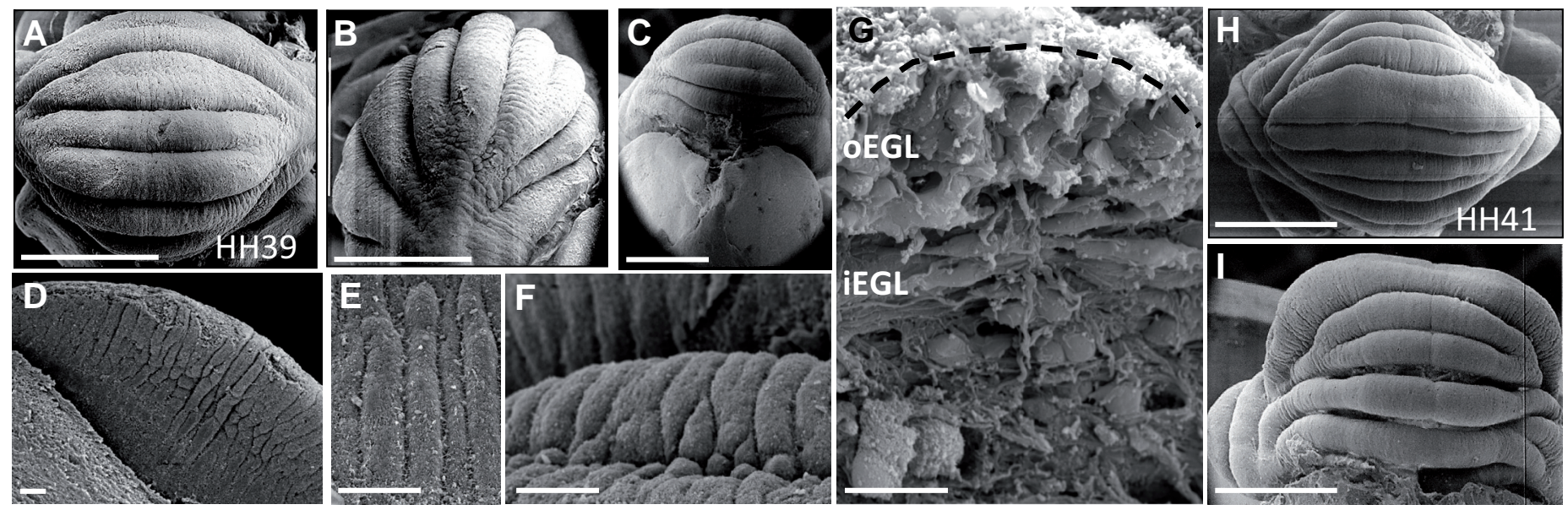

Fig. 1. Scaning electron micrographs of the chick cerebellum. Embryos at HH39 (A-G) and HH41 (H, I) stages were studied. In (A,B,C), the cerebellum is shown at its dorsal (A), lateral (B) and rostral (C) side. (D) One of the folia was dissected to reveal the morphology of indentations as longitudinal bands (E) or irregular bulges (F). The internal citoarchitecture is exposed in a broken folia (G), where the oEGL (rounded cells radially oriented), and the iEGL (fusiform cells horizontally oriented) can be clearly identified. The dashed line delineates the external curvature of an indentation. At stage HH41, the sharpness of indentations diminish as observed in the dorsal(H) and rostral (I) cerebellar surface. Abbreviations: oEGL, outermost stratum of the external granule cell layer; iEGL, innermost part of the external granule cell layer. Calibration bars represent $100 \mu \mathrm{m}$ in all the pictures, except in $\mathrm{G}(\mathrm{bar}, 10 \mu \mathrm{m})$. 

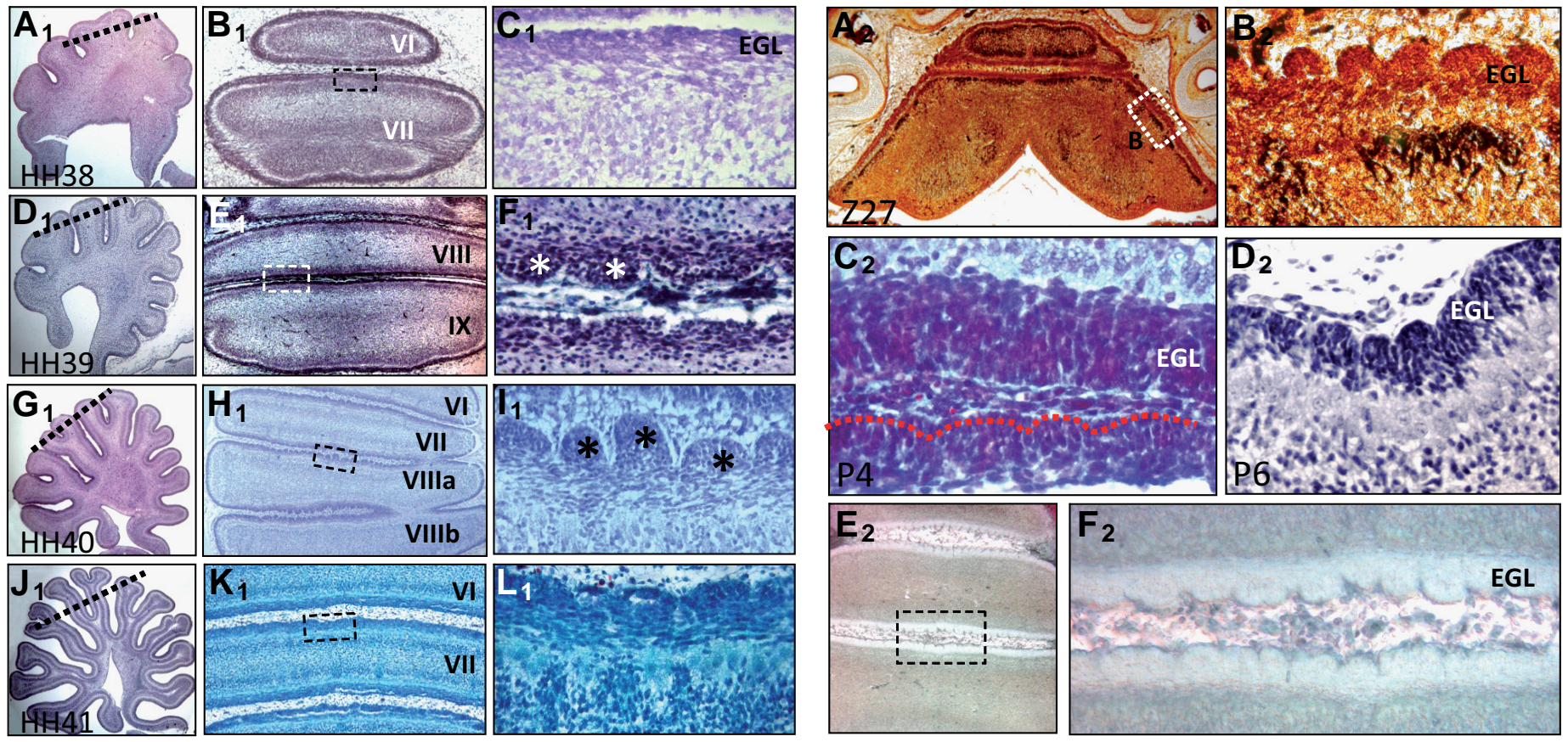

Fig. 2. Changes in the external granule layer (EGL). $\left(\mathbf{A}_{\mathbf{1}}-\mathbf{L}_{\mathbf{1}}\right)$ Paraffin HE stained sections, throughout stages $H H 38\left(\mathbf{A}_{\mathbf{1}}, \mathbf{B}_{\mathbf{1}}, \mathbf{C}_{\mathbf{1}}\right), H H 39\left(\mathbf{D}_{\mathbf{1}}, \mathbf{E}_{\mathbf{1}}, \mathbf{F}_{\mathbf{1}}\right)$, HH4O $\left(\mathbf{G}_{\mathbf{1}}, \mathbf{H}_{\mathbf{1}}, \mathbf{I}_{\mathbf{1}}\right)$ and HH41 $\left(\mathbf{J}_{\mathbf{1}}, \mathbf{K}_{\mathbf{1}}, \mathbf{L}_{\mathbf{1}}\right)$. Sagittal sections $\left(\mathbf{A}_{\mathbf{1}}, \mathbf{D}_{\mathbf{1}}, \mathbf{G}_{\mathbf{1}}, \mathbf{J}_{\mathbf{1}}\right)$ illustrate the increase in the cortical surface as well as the fissuration pattern through the cerebellar cortex development. Sections taken at the orientation shown by dashed lines $\left(\mathbf{B}_{\mathbf{1}}, \mathbf{E}_{\mathbf{1}}, \mathbf{H}_{\mathbf{1}}, \mathbf{K}_{\mathbf{1}}\right)$ evidence the transient character of indentations. Enlargements of squared regions allow identification of indentations in the EGL, marked by asterisks in $\left(\mathbf{F}_{\mathbf{1}}, \mathbf{I}_{\mathbf{1}}\right)$. Indentations in quail paraffin sections. $\left(\mathbf{A}_{\mathbf{2}}-\mathbf{F}_{\mathbf{2}}\right.$ ) Indentations in quail paraffin sections (Stage Z27) stained with Bielchowsky $\left(\mathbf{A}_{\mathbf{2}}, \mathbf{\mathbf { B } _ { \mathbf { 2 } }}\right.$ ) and mouse (P4, $\left.\mathbf{P 6} \mathbf{6}\right) \mathrm{HE}$ stained sections $\left(\mathbf{C}_{\mathbf{2}}, \mathbf{D}_{\mathbf{2}}\right)$. Dashed line in $\left(\mathbf{C}_{\mathbf{2}}\right)$ delineates the external shape of indentations. In $\left(\mathbf{E}_{\mathbf{2}}\right)$, a vibratome section of chick cerebellum at HH4O included in gelatinealbumin demonstrates the presence of indentations in not dehydrated specimens; see enlargement in $\left(\mathbf{F}_{\mathbf{2}}\right)$.

in the the adult a network where it can be distinguished different types of vessels (Duvernoy et al. 1983).

In this work, after discarding the possibility that indentations were mere artefacts, we have described its external appearance and citoarchitecture in avians and mammals at stages of development in which thickness of the EGL is maximal. The transient character of this phenomenon propiciated the study of factors affecting both proliferation and migration of granule cell progenitors. Our data indicate that the formation of granular cell raphes and radial glia fiber distribution, involved in migration, are not morphologically correlated with indentations. However, the fragmented pattern of expression of Shh, observed prior to the indentations, suggests that PCs play a role in its formation through the activation/maintenance of the mitotic activity of cells in the EGL. In addition, the development of intracortical vascular patterning was coupled in time to the increase in thickness of the oEGL, being involved in the morphogenesis of the characteristic transient architecture of this layer.

\section{Results}

\section{Description of indentations in vertebrates}

The study of developmental changes in the external surface of the chick cerebellum by scanning electronic microscopy revealed the transient appearance of longitudinal furrows and bulges along the folia (Fig. $1 \mathrm{~A}-\mathrm{F}, \mathrm{H}, \mathrm{I}$ ). The smooth cerebellar surface of the folia observed at $\mathrm{HH} 38$ is transformed at $\mathrm{HH} 39$ into a wrinkled one, showing clear bulking strips (Fig. $1 \mathrm{~A}-\mathrm{F}$ ). From HH41 onwards, signs of this pattern start to disappear. When the surface of one of the folia is exposed, it is evidenced that most of its extension shows bands (Fig. 1D) with longitudinal trajectories in some areas (Fig. 1E) and irregular pattern in others (Fig. 1F). The study of the internal structure of folia can be observed after a fracture (Fig. $1 \mathrm{G})$, revealing that bands affect exclusively the outermost part of the external granule layer (oEGL). It is noticeable that cells in this layer are disposed radially. Underneath, the granule postmitotic fusiform cells are oriented horizontally forming the iEGL. From its external appearance, bulkiness of cerebellar surface affects to all the folia.

The histological analysis confirms that bands appear in a transient period including developmental stages $\mathrm{HH} 38-\mathrm{HH} 41$, and also that oEGL is the cortical layer involved in this morphological pattern (Fig. $2 A_{1}-L_{1}$ ). In sections, bands appear as teethlike structures that we will call indentations, clearly evident at $\mathrm{HH} 40$ (Fig. 2l $\mathrm{I}_{1}$ ).

We were aware of the strong dehydratation process that samples must undergo for the scanning microscopy and histological preparations. In order to avoid a wrong analysis of this morphological feature, we explore the presence of indentations in vibratome sections of specimens included in gelatin:albumin, to discard a possible artefact originated by technical procedures. As expected, these indentations were clearly observed at $\mathrm{HH} 40$ in these poorly dehydrated sections (Fig. $2 \mathrm{E}_{2}, \mathrm{~F}_{2}$ ).

The pattern observed in chickens is also detected at the corresponding stages of cerebellar development in the quail (Z27) and mouse (P5) (Fig. 2 A-F). 


\section{Morphometric study of the external granule layer (EGL)}

Cortical layers at stage HH38 include the EGL with its two histological subdivisions (oEGL rounded cells and iEGL fusiform cells), the molecular layer constituted by parallel fibers and axons of differentiating and migrating granule cells and the Purkinje cell layer in the deeper stratum (Fig. $3 C$ ). Cells in the oEGL undergo mitotic activity, evidenced by BrdU incorporation (Fig. 3 A,B). The iEGL contains postmitotic granule cells that migrate inwards until reaching the depth of Purkinje cells (Fig. $3 \mathrm{E}$ ), where finally differentiate, expressing high levels of the neuronal specific nuclear protein (NeuN) (Weyer and Schilling, 2003) (Fig. 3D).

Variations in the thickness of the EGL were studied along development by measures at both upper and intermediate caudal levels of the prepyramidal fissure. The data shows a progressive increase in thickness of the EGL to reach a peak at HH39 (Fig. 3F). Similar results were obtained with the two measures, indicating that horizontal sections affecting different DV levels are comparable.

\section{Migration of granule cells. Raphes and its relation to Bergmann glia}

Postmitotic granule cells accumulate underneath the mitotic component of the EGL, acquire a bipolar shape and horizontal orientation, and finally migrate deep to populate the inner granular cell layer (IGL). By this mechanism, the EGL becomes empty with time leading to the adult pattern of cortical layers. The migration of granule cells occurs through specific pathways called raphes that can be first observed at HH35. The pattern of raphes was studied by detection of a granule specific marker Zic1 (Aruga et al. 1996) as illustrated in Fig. 4 A-E.

Our interest in the study of raphes was to compare its pattern with the formation of bands in the EGL, in an attempt to relate spatially and temporally two processes: 1 - the emptying of the layer by migration and 2- the formation of indentations. However, although the number of raphes increases during a period that includes the appearance of indentations ( $\mathrm{HH} 35-\mathrm{HH} 41)$, we did not find a clear correlation between both phenomena (Fig. 4C).

On the other hand, it is documented that migration of granule cells occurs on Bergmann glial fibers. Detection of these fibers at $\mathrm{HH} 38-\mathrm{HH} 41$ was done by BLBP (brain lipid-binding protein) positive immunoreactivity (Lewis et al. 2004). The results indicate that BLBP positive glia is poorly detected at $\mathrm{HH} 38$ (Fig. 4F) becoming stronger as development progresses (Fig. 4 G-I), when acquires a pattern in palisade with a homogeneous distribution in the EGL. In other words, the furrows of indentations are not correlated with a specific distribution of glial fibers (Fig. 4 F-I).
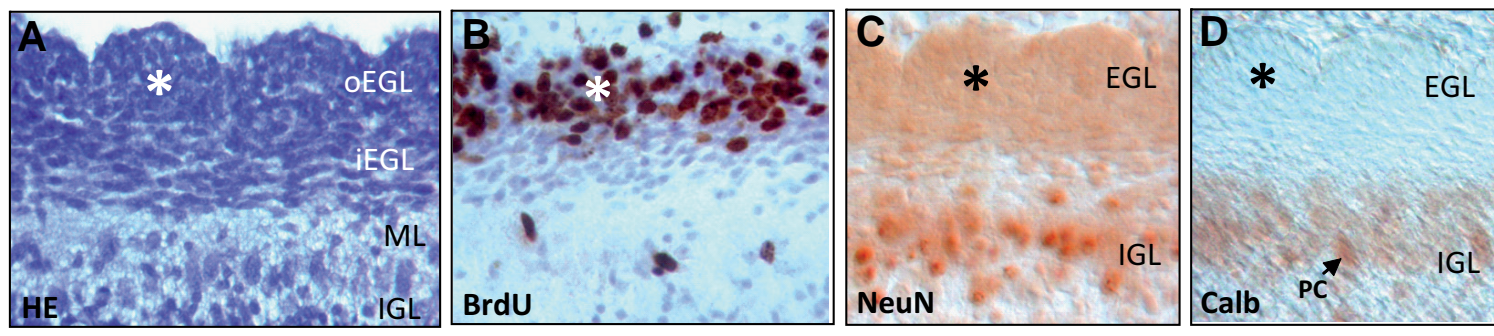

E
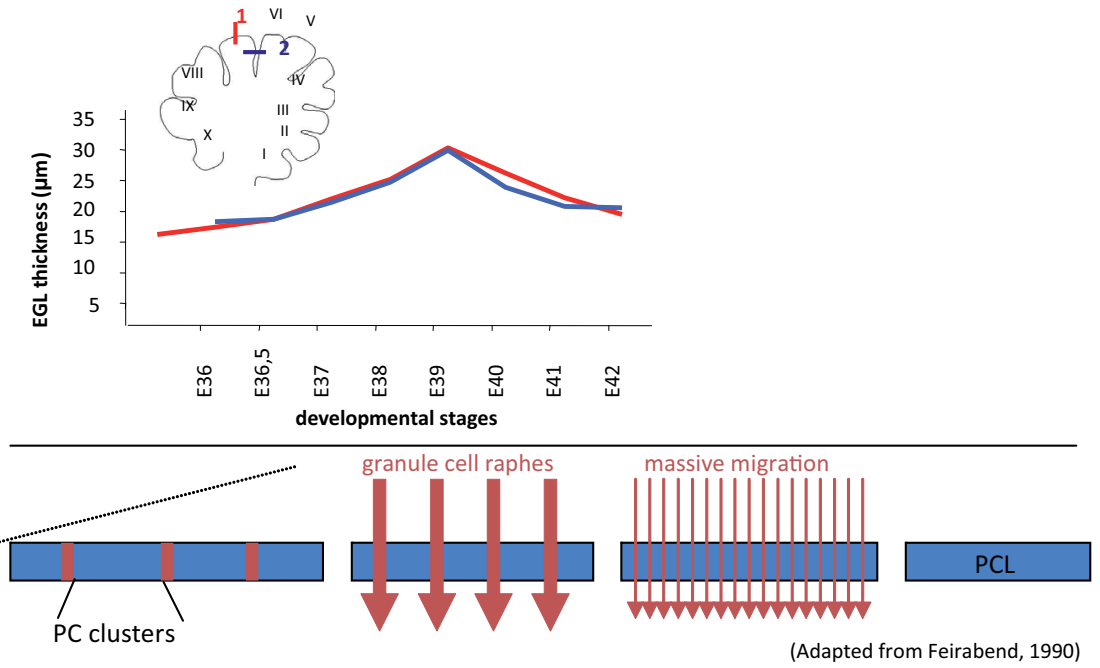

Fig. 3. Molecular characterization of cortical cerebellar layers. HH4O chick embryos were used to study molecular characterization and changes in thickness. The histological features of the EGL, including indentations, are observed in a HE stained section (A). Proliferating cells visualized by BrdU incorporation (B) appear in the outermost substratum of the EGL (oEGL). Postmitotic migrated cells that form the IGL were identified by immunoreactivity against NeuN (C), while Purkinje cells were reactive to the specific marker calbindin (D). (F) Quantitative analysis of the EGL changes in thickness through developmental stages (E35-E42). Two measures were taken: at the upper level of the folium VIII (1, red line) and at the caudal middle level of the prepyramidal fissure $(2$, blue line). The timing of both Purkinje cell clustering and the granule cell raphe formation is coupled underneath of the graphic. Abbreviations: EGL, external granule cell layer; iEGL, inner part of the EGL; ML, molecular layer; IGL, internal granule cell layer; PC, Purkinje cells. Asterisks indicate indentations. 

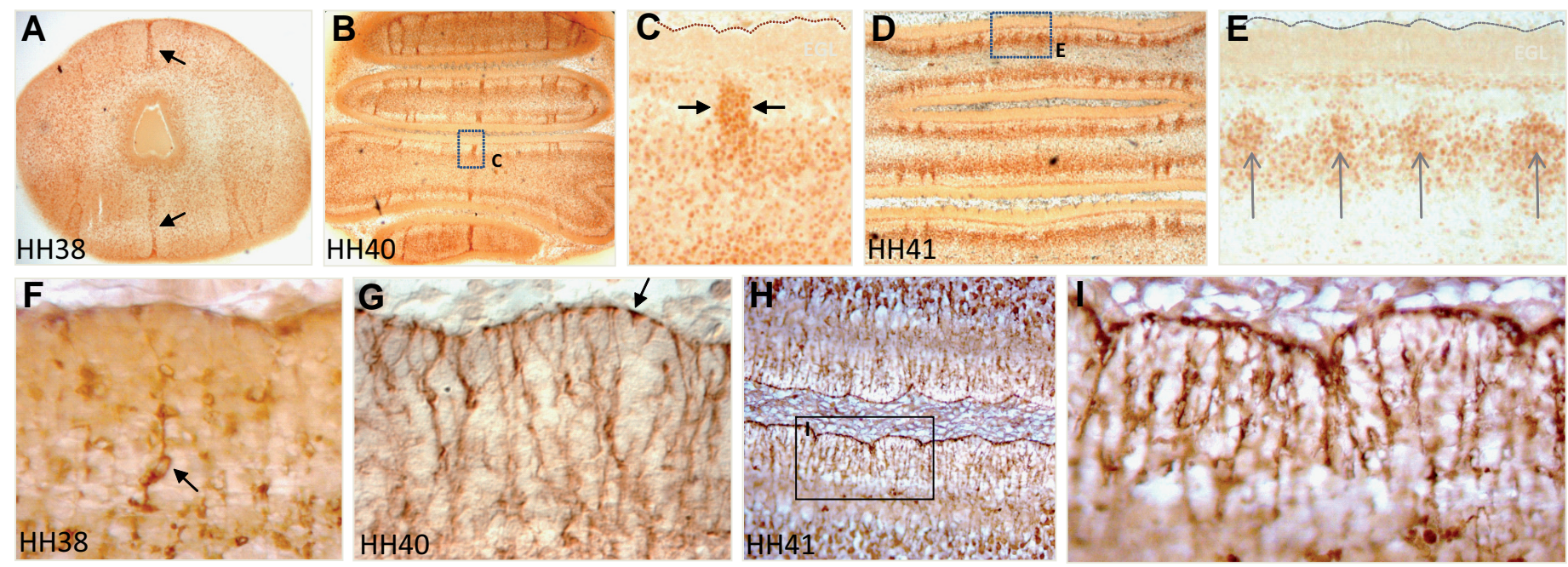

Fig. 4. External granule layer migratory pathways. The ribbons of migrating granule cells or "raphes" were evidenced by the immunodetection of the granule cell marker Zic-1 (A-E). Arrows in (A,C,D) indicate the position of raphes. (C) An enlargement of the framed region shown in (B). There is a progressive increase in the number of raphes between $\mathrm{HH} 38$ and $\mathrm{HH} 41$ stages, although their positions do not correlate with either bulges or furrows in the EGL at any stage (C,E). Pointed line in (C,E) outlines the pial border of the folia. The disposition of the Bergmann glial fibers throughout the EGL was studied by BLBP immunodetection at the same stages than the raphes (F-I). Glial cells (arrow in F) emit prolongations that reach the surface as endfeets (arrow in G). The pictures reveal that glial cells form a fiber palissade in the EGL (G-I) but no relation to the morphology of indentations is observed. An enlargement of the region framed in (H) can be observed in (I).

\section{Influence of Purkinje cells on external granule cells. Prolif- eration and indentations}

We have studied the pattern of expression of Shhduring chick cerebellar development. Shh, an essential factor for both proliferation and appropriate expansion of granule cell neuroblasts to form the EGL, is expressed by Purkinje cells. The transcripts were observable at stage HH39 in clusters of Purkinje cells (PCs). However, this pattern observed at $\mathrm{HH} 39$ does not correspond to any sign of indentation in the EGL (Fig. $5 \mathrm{~A}, \mathrm{~B}$ ). The analysis of Shh expression pattern at stage $\mathrm{HH} 40$, the time at which indentations become very prominent, revealed an increase in the number and level of expression of Shhpositive cells, although not all of them are distributed in clusters but they form a more homogeneous layer (Fig. 5 C,D) that remained visible at least until $\mathrm{HH} 41$ where PCs form a continuous layer underneath the EGL (Fig. 5 E,F).

\section{External granule layer indentations are related to the early pattern of cerebellar vascularization}

A detailed observation of the histological sections indicated that vessel-like structures were positioned at the intersection of two indentations (Fig. 6A). Laminin stains both meningeal cells and basal membrane covering the EGL. The pattern observed clearly shows that vessels penetrate in the EGL at the furrows of indentations at $\mathrm{HH} 40$ (Fig. $6 \mathrm{~B}, \mathrm{C}$ ). This data demonstrate that furrows are the points where vessels extend inwards from the pial surface, going through the EGL. In fact, the study of the vascular pattern between the stages $\mathrm{HH} 39-\mathrm{HH} 41$ indicates that distribution of vessels is perfectly adjusted to the development of indentations (Fig. 6 $D, E, G, H)$. Then, at $H H 39$, the laminin positive ves- sels are sparsely observed (Fig. 6D) while they become more numerous at $\mathrm{HH} 40$ (Fig. 6E), starting to be found at the furrows of the EGL indentations. Coincident with an increase in number of indentations, vessels also increase in number and are exclusively attached to the furrows forming a palisade pattern as observed in transverse sections (Fig. $6 \mathrm{G}, \mathrm{H}$ ). The tubular character of the vessels, that penetrate in right angle from the surface, is illustrated in Fig. 6 F,I. The rectilinear trajectory of vessels until they reach the Purkinje cell layer, where they bifurcate, is observed in Fig. 6 D,E,G.

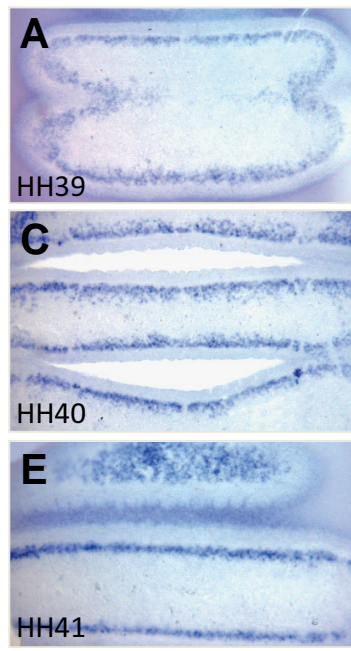

Fig. 5. Shh expression pattern in the cortex. At HH39, when indentations are not evident, clusters of Purkinje cells expressing Shh can be clearly identified (A); see curved lines in (B). At HH40, indentations are clear in the EGL (C); see asterisks in (D), at the time the clusters of Shh expressing Purkinje cells have almost disappeared; see curved lines in (D). Later in development (HH41), the Purkinje cell layer (PCL) differentiates becoming thinner, at the time the indentations are much less prominent $\mathbf{( E ,} \mathbf{F})$. 

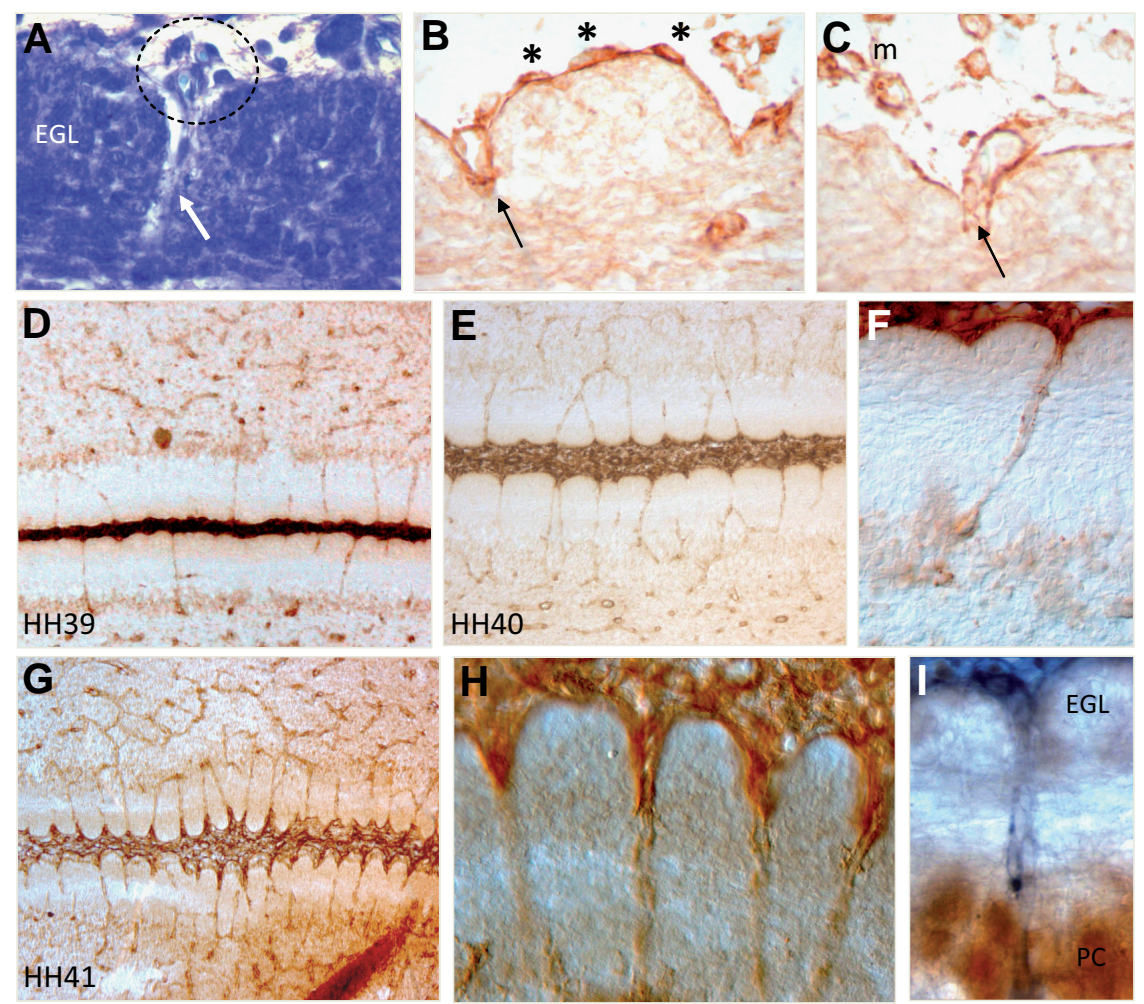

Fig. 6. Vascular pattern of the embryonic cerebellar cortex. (A) Histological section showing a detailed view of the EGL, where a group of cells positioned between two indentations (dashed line) can be observed. Vessel-like structures, see arrows in (A-C) can be identified in HE stained (A) as well as in laminin labelled sections (B,C). Asterisks in (B) indicate meningeal cells apposed on the surface of an indentation. Progressive formation of the vascular pattern is observed by immunodetection of laminin in $(\mathbf{D}, \mathbf{E}, \mathbf{G})$. The rectilinear trajectory of vessels penetrating the EGL is clearly observed in (F). In (I), it can be observed how vessels reach the Purkinje cell layer (blue, laminin; brown, calbindin). The striking relation between the sharp profile of indentations and the entry of vessels at furrows, as well as the close relation between cells of the oEGL and the basal lamina $\mathbf{( H )}$, is noticeable. Abbreviations: m, meningeal cells; PC, Purkinje cells.

\section{Discussion}

In this study, we have shown that indentations are present in the chicken cerebellar cortex during a transient period of time, involving exclusively the outermost stratum of the external granular cell layer (oEGL). Histological preparations demonstrated that the same phenomenon appears in quail and mouse cerebella, at comparable stages of development $(\mathrm{HH} 39$ in chicken; $\mathrm{Z} 27$ in quail and P5 in mouse). These data suggest that indentations are involved in the morphomechanic process of cerebellar cortex expansion, mainly carried out by the granule cells in the oEGL, a numerous and highly proliferative cell population.

The EGL is formed by two different layers of granular cells: an external, proliferative, densely packed round cells (oEGL) and a nonproliferative layer of fusiform cells that accumulate forming the innermost substratum (iEGL). The latter cell population remains transversely oriented until its inward migration through the Purkinje cells to finally form the internal granular layer (IGL) (Feirabend, 1990; Altman and Bayer, 1996). This multistep process in that proliferation, migration and differentiation events occur, seems to be required to achieve the correct formation of the layered cerebellar cortex. Within this context, we discuss here several factors that could be involved in the morphogenesis of indentations.

Since indentations show a highly regular pattern affecting the cortex, they remember the "granule cell raphes" or ribbons of granule cells moving radially from the $\mathrm{OEGL}$ to populate the IGL (Karam et al. 2001; Luckner et al. 2001). Then, we first paid attention to a possible coincidence between the migratory pathways of EGL cells and the appearance of furrows in the cortex. In fact, the raphes and indentations are both transient phenomena, with an overlapping developmental window that coincides with the migration of oEGL cells. Nevertheless, in spite of these similarities, our data does not provide evidence of a spatial correlation between the formation of raphes and furrows, suggesting that the latter do not form as consequence of the granular cell migrations.

On the other hand, a massive and diffuse migration of granule cell precursors occurs along radial glial fibers (Hatten, 1999) organized in vertical palisades (Altman, 1975; de Blas, 1984). This migration is characteristic of later stages of development, resulting in the depletion of the embryonic EGL that disappears shortly after birth. We studied the distribution of radial fibers by immunodetection of BLBP in order to address if the radial pattern of glial fibers and the formation of furrows would be related. We confirmed the presence of these fibers, and attached to them we found cells that appear to use them as scaffold in their inward migratory routes. However, our data do not support a relation between radial fiber distribution and the bulked pattern of the EGL, indicating that inward migration is not a factor involved in the morphological process of formation of indentations in the oEGL.

In a second approach, we considered the great proliferative activity of $E G L$ as a possible origin of cortical bulking. To address whether mitotic activity was activated in the EGL during the phase in that indentations appear, we study the pattern and number of labelled cells by BrdU incorporation at this phase. In spite of the overall increase in thickness of the EGL along cortical development, as reported by Feirabend (1990), our data do not reveal a pattern of actively dividing clusters of cells, what could be associated to bulge formation in the oEGL.

In this context, we have to consider that Purkinje cells (PCs) play a critical role in the proliferative activity of granule cell progenitors by producing Shh (Herrup, 1983; Smeyne et al. 1995; Wallace, 1999; Wechsler-Reya and Scott, 1999). In fact, it was reported that Shh overexpression results in an oversized cerebellum, apparently due to a prolonged period of proliferation of granule cell progenitors, what correlated with the emergence of irregularities in the thickness of the IGL, while basic foliation pattern was normal (Corrales et al. 2004). In this study, we have been able to demonstrate the presence of clusters of Purkinje neuroblast cells expressing Shh. The fragmented pattern of the PC layer by regularly distributed clusters of Shhexpressing cells 
preceded the formation of indentations, suggesting a possible relation between the presence of this mitogenic factor and the nearness of bulging in the oEGL. However, as mentioned above, the pattern of proliferation we observed within the oEGL was not clustered but quite homogenous, not supporting a spatial connection between Shh expressing cells and groups of dividing cells that could result in the appearance of bulges.

Discontinuities in the Purkinje neuroblast cel layer revealed by Shh expressing cells, the indentations affecting the oEGL, and the granular cell migratory pathways or "raphes" among others, demonstrate that fragmentation seems to be a quality of the cortical layer. According to this idea, and assuming the data reported in the literature about the early pattern of cerebellar vascularization (Conradi et al. 1980; Duvernoy et al. 1983), our next approach in the present study was to analyse in detail the pattern of blood vessels penetrating in the embryonic cerebellar cortex.

Our data evidenced that the EGL territory is first subdivided into wide areas (before $\mathrm{HH} 39$ ) due to the scattered number of ingrowing vessels but later $(\mathrm{HH} 40$ and $\mathrm{HH} 41)$, when indentations became visible, laminin immunoreactivity revealed a vascular pattern much more defined, whith radial vessels limiting regular territories in the oEGL. The indentations now appeared delineated by both pial vascular network and vessels that penetrate into the furrows until the Purkinje cell layer, where they branch according to most authors (Conradi et al. 1980; Duvernoy et al. 1983; Yoshida et al. 1985). The oEGL acquired at this stage the profile of a well defined outer bulging shape.

These data indicate that the cytoarchitecture of the cortical region depends not only on events as proliferation and migration but also on the formation of the overlying pial vascular plexus, and the following penetrating vessels. Stimulating migration is part of several possible mechanisms by which meningeal cells might exert their influence on cortical development. Thus, several lines of evidence suggest that extracellular matrix (ECM) molecules secreted by meningeal cells are essential in regulating EGL proliferation: laminin, their ligands $\beta 1$ Integrins and proteoglycans enhance the ability of Shh to induce granule cell progenitor proliferation (Blaess et al. 2004).

In addition, meningeal cells and the pial basement membrane play an essential role in stabilizing the cerebellar surface since its destruction leads to abnormal lamination and foliation of the cerebellum (Sievers et al. 1986, Halfter et al. 2002) Morphogenesis of the cerebellar cortex also depends on the activity of matrix metalloproteinases by catalizing the degradation of all the protein constituents of the cell-extracellular matrix interactions (Ayoub et al. 2005; Luo 2005).

In summary, we have described a temporal pattern of the EGL growth, that modifies the external surface of the folia and reflects the coordination of events such as proliferation, migration and vascularization as well as the relation between different types of neuron precursors during development. This coordination might be at the service of the highly organized connectivity of the cerebellar functional units.

\section{Materials and Methods}

\section{Animals}

Chicken and quail embryos were obtained from fertilized eggs purchased from Granja Santa Isabel (Córdoba, Spain). Eggs ranging from 9 to 15 days of incubation) were cooled for $10-15 \mathrm{~min}$ on ice to induce anaesthesia before being opened. Chick embryos were staged according to the morphological criteria of Hamburger and Hamilton (1951). Quail embryos ( $n=3$ were used at stages Z24-Z29 (Zacchei, 1961), comparable to the mentioned chicken stages. For the study in mouse $(n=3), C 57 B L /$ $6 \mathrm{~J}$ specimens were used at postnatal P0-P8 stages.

\section{Scanning electronic microscopy}

The chicken cerebella ( $n=4$ for each stage) were dissected and fixed in $1 \%$ glutaraldehyde in PBS for $24 \mathrm{hr}$ at $4^{\circ} \mathrm{C}$. After washes in PBS, the specimens were secondary fixed for $1 \mathrm{hr}$ in $4 \%$ osmium tetroxide in $\mathrm{dH}_{2} \mathrm{O}$, washed and dehydrated in an increasing series of acetone: $\mathrm{dH}_{2} \mathrm{O}$ before to be transferred to the critical point dryer Hitachi HCP-1. Dehydrated specimens were coated with gold in a Jeol Fine Coat lon Sputter JFC1100 , and samples analysed on an scanning electron microscope Jeol JSM-35CF.

\section{Histology. Immunohistochemistry and antibodies. Proliferation}

Standard procedures for haematoxylin-eosin, Nissl, Bielchowsky and trichromic $(0.13 \%$ light green SF yellowish, $0.16 \%$ orange G, $0.2 \%$ Fuchsin acid) staining methods were used on $7 \mu \mathrm{m}$ thick paraffin sections. For immunohistochemistry, both paraffin and gelatine-albumin vibratome $(50 \mu \mathrm{m})$ sections were used. Formalin-fixed paraffin embedded tissue required epitope retrieval protocols, utilizing citrate buffer, EDTA or enzymatic methods depending on the antibody requirements. Primary antibodies: Calbindin (1/5000, Swant), NeuN (1/100, Chemicon), Zic-1 (1/ 400, Rockland), PCNA (1/75, Chemicon), BLBP (1/500, Chemicon), laminin (1/50, Sigma). Secondary antibodies: donkey anti-mouse IgG biotin (Chemicon), donkey anti-rabbit IgG biotin (Chemicon), goat antirabbit IgG AP (Jackson). For the proliferation study, the 5-bromo-2' deoxy-uridine detection Kit II (Roche) was used following the manufacturer's instructions. BrdU $(200 \mu \mathrm{l}$, stock: $2 \mathrm{mg} / \mathrm{ml})$ was injected in the yolk of chicken embryos $2 \mathrm{hr}$. before sacrificing them. A number of 8 cerebellums of each stage of development were used for this study.

\section{Morphometric study}

The thickness of the external granule cell layer (EGL) was measured on midsagittal paraffin sections at $\mathrm{HH} 36-\mathrm{HH} 43$ stages $(n=5$ of each stage). To select representative midsagittal sections from each cerebellum, we chose those with the higher ventricular area. On these sections, we registered the DV length of the EGL in $\mu \mathrm{m}$, as a measure of thickness, at both the upper and medial levels of the prepyramidal fissure. Data was obtained from 25 midsagittal sections per stage. The software for the morphometric analysis was VIDS-4.

\section{In situ hybridization}

Cerebellar vibratome sections $(50 \mu \mathrm{m})$ were processed for freefloating in situhybridization as previously described (Blanco et al. 2002). Shh digoxigenin-UTP labelled riboprobe was synthetized by using cDNA kindly provided by F. Unda (Universidad del País Vasco) and described elsewere. Four chick cerebella of each HH39-41 stage were used for this experiments.

\section{Acknowledgements}

We are specially grateful to Dr. Marc Rodriguez-Niedenfuhr for comments and discussions that have highly improved the paper. This work was supported by a grant of the Spanish Ministry of Education and Science (BFU2006-15245BFI) to M. J. B.

\section{References}

ALTMAN J. (1975). Postnatal development of the cerebellar cortex in the rat. IV Spatial organization of bipolar cells, parallel fibers and glial palisades. J Comp Neuro/163: 427-447. 
ALTMAN J. and BAYER S.A. (1996). Development of the cerebellar system in Relation to its Evolution, Structure and Functions. New York: CRC Press.

ARUGA J., NAGAI T., TOKUYAMA T., HAYASHIZAKI Y., OKAZAKI Y., CHAPMAN V.M. and MIKOSHIBA K. (1996). The mouse zic gene family. Homologues of the Drosophila pair-rule gene odd-paired. J Biol Chem 271: 1043-1047.

AYOUB A.E., CAIE T., KAPLAN R.A. and LUO J. (2005). Developmental expression of matrix metalloproteinases 2 and 9 and their potential role in the histogenesis of the cerebellar cortex. J Comp Neuro/481:403-415.

BLAESS S., GRAUS-PORTA D., BELVINDRAH R., RADAKOVITS R., PONS S., LITTLEWOOD-EVANS A., SENFTEN M., GUO H., LI Y., MINER J.H., REICHARDS L.F. and MULLER U. (2004). $\beta 1$ Integrins are critical for granule cell precursor proliferation. J Neurosci24: 3402-3412.

BLANCO M.J., PEÑA-MELIÁN A. and NIETO M.A. (2002). Expression of EphA receptors and ligands during chick cerebellar development. Mech Dev114:225229.

CONRADI N.G., ENGVALL J. and WOLFF J.R. (1980). Angioarchitectonics of rat cerebellar cortex during pre- and postnatal development. Acta Neuropatho/50: 131-138.

CORRALES J.D., ROCCO G.L., BLAESS S., GUO Q. and JOYNER A.L. (2004). Spatial pattern of sonic hedgehog signaling through Gli genes during cerebellum development. Development 131: 5581-5590.

DE BLAS A.L. (1984). Monoclonal antibodies to specific astroglial and neuronal antigens reveal the cytoarchitecture of the Bergmann glia fibers in the cerebellum. JNeurosci 4: 265-273.

DUVERNOY H., DELON S. and VANNSON J.L. (1983). The vascularization of the human cerebellar cortex. Brain Res Bull11: 419-480.

FEIRABEND HK (1990). Development of longitudinal patterns in the cerebellum of the chicken (Gallus domesticus): a cytoarchitectural study on the genesis of cerebellar modules. Eur J Morpho/28: 169-223.

GOODRICH L.V., MILENKOVI L., HIGGINS K.M. and SCOTT M.P. (1997). Altered neural cell fates and medulloblastoma in mouse patched mutants. Science277: 1109-1113.

HALFTER W., DONG S., YIP Y.P., WILLEM M. and MAYER U. (2002). A critical function of the pial basement membrane in cortical histogenesis. JNeurosci22: 6029-6040.

HANAWAY J. (1967). Formation and differentiation of the external granular layer of the chick cerebellum. J Comp Neuro/131:1-14.

HATTEN M.E. and HEINTZ N (1995). Mechanisms of neural patterning and specification in the developing cerebellum. Annu Rev Neurosci 18: 385-408.

HATTEN M.E. (1999). Central nervous system neuronal migration. Annu Rev
Neurosci22: 511-539

HERRUP K. (1983). Role of staggerer gene in determining cell number in cerebellar cortex. I. Granule cell death is an indirect consequence of staggerer gene action. Brain Res 313: 267-274.

KARAM S.D., KIM Y.S. and BOTHWELL M. (2001). Granule cells migrate within raphes in the developing cerebellum: an evolutionarily conserved morphogenic event. J Comp Neuro/440: 127-135.

LEWIS P.M., GRITLI-LINDE A., SMEYNE R., KOTTMANN A. and MCMAHON A.P (2004). Sonic hedgehog signaling is required for expansion of granule neuron precursors and patterning of the mouse cerebellum. Dev Bio/270: 393-410.

LUCKNER R., OBST-PERNBERG K., HIRANO S., SUZUKI S.T. and REDIES C. (2001). Granule cell raphes in the developing mouse cerebellum. Cell Tissue Res 303: 159-172.

LUO J. (2005). The role of matrix metalloproteinases in the morphogenesis of the cerebellar cortex. The Cerebellum 4: 239-245.

SIEVERS J., von KNEBEL DOEBERITZ C., PEHLEMANN F.W. and BERRY M. (1986). Meningeal cells influence cerebellar development over a critical period. Anat Embryol 175: 91-100

SMEYNE R.J. and GOLDOWITZ D. (1989). Development and death of external granular layer cells in the weaver mouse cerebellum: a quantitative study. $J$ Neurosci9: 1608-1620.

SMEYNE R.J., CHU T, LEWIN A., BIAN F., SANLIOGLU S., KUNSCH C., LIRA S.A. and OBERDICK J. (1995). Local control of granule cell generation by cerebellar Purkinje cells. Mol Cell Neurosci6: 230-251.

WALLACE V.A. (1999). Purkinje-cell-derived Sonic hedgehog regulates granule neuron precursor cell proliferation in the developing mouse cerebellum. Curr Bio/9: 445-448.

WECHSLER-REYA R.J. and SCOTT M.P. (1999). Control of neuronal precursor proliferation in the cerebellum by Sonic Hedgehog. Neuron 22: 103-114.

WEYER A. and SCHILLING K. (2003). Developmental and cell type-specific expression of the neuronal marker NeuN in the murine cerebellum. JNeurosci Res 73: 400-409.

WURMSER A.E., PALMER T.D. and GAGE F.H. (2004). Cellular interactions in the stem cell niche. Science 304: 1253-1255.

YOSHIDA Y., IKUTA F., WATABE K. and NAGATA T. (1985). Developmental microvascular architecture of the rat cerebellar cortex. Anat Embryo/171: 129138.

ZACCHEI A.M. (1961). The embryonal development of the Japanese quail ( Coturnix coturnix japonica). Arch Ital Anat Embrio/66: 36-62. 


\section{Further Related Reading, published previously in the Int. J. Dev. Biol.}

See Special Issue Pattern Formation edited by Michael K. Richardson and Cheng-Ming Chuong at: http://www.ijdb.ehu.es/web/contents.php?vol=53\&issue =5-6

Key apoptosis regulating proteins are down-regulated during postnatal tissue development Shane D. Madden, Maryanne Donovan and Thomas G. Cotter Int. J. Dev. Biol. (2007) 51: 415-424

Expression of FoxP2 during zebrafish development and in the adult brain Rina Shah, Olga Medina-Martinez, Li-Fang Chu, Rodney C. Samaco and Milan Jamrich Int. J. Dev. Biol. (2006) 50: 435-438

Developmental expression of Xenopus Fragile $X$ mental retardation-1 gene Jae H. Lim, Ting Luo, Thomas D. Sargent and Justin R. Fallon Int. J. Dev. Biol. (2005) 49: 981-984

Isthmus organizer and regionalization of the mesencephalon and metencephalon Harukazu Nakamura and Yuji Watanabe Int. J. Dev. Biol. (2005) 49: 231-235

Cerebellar histogenesis as seen in identified cells of normal-reeler mouse chimeras A Yoshiki and M Kusakabe Int. J. Dev. Biol. (1998) 42: 695-700

Soluble and membrane-bound pyroglutamyl-peptidase I activity in the developing cerebellum and brain cortex J M de Gandarias, J Irazusta, M Silio, J Gil, N Saitua and L Casis Int. J. Dev. Biol. (1998) 42: 103-106

Perinatal development of rat cerebellum from adrenalectomized mothers I Cuchillo, J L Trejo, C Machin and C Rua Int. J. Dev. Biol. (1996) 40: S263-S264

Developmental expression of neurofilament and glial filament proteins in rat cerebellum L A Sawant, N N Hasgekar and L S Vyasarayani Int. J. Dev. Biol. (1994) 38: 429-437

Aminopeptidase activity levels during axonal and dendritic growth in the rat brain J M de Gandarias, J Irazusta, E Echevarría, E San Martín and L Casis Int. J. Dev. Biol. (1992) 36: 583-585

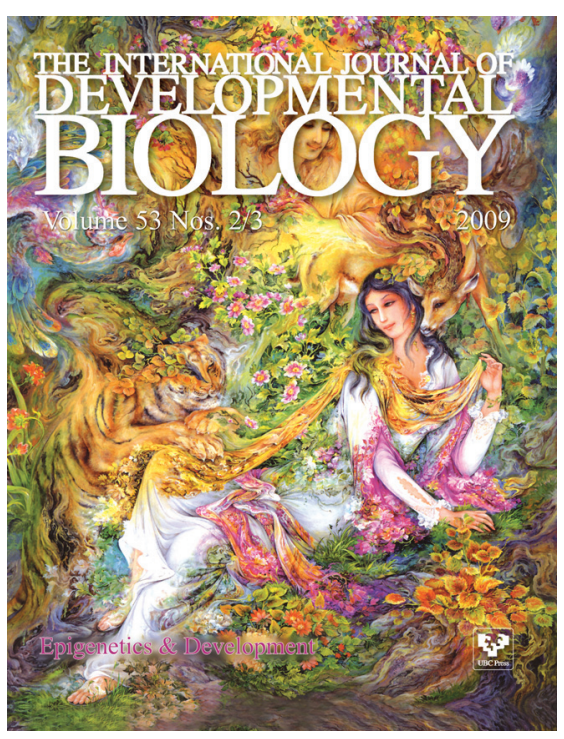

5 yr ISI Impact Factor $(2008)=3.271$

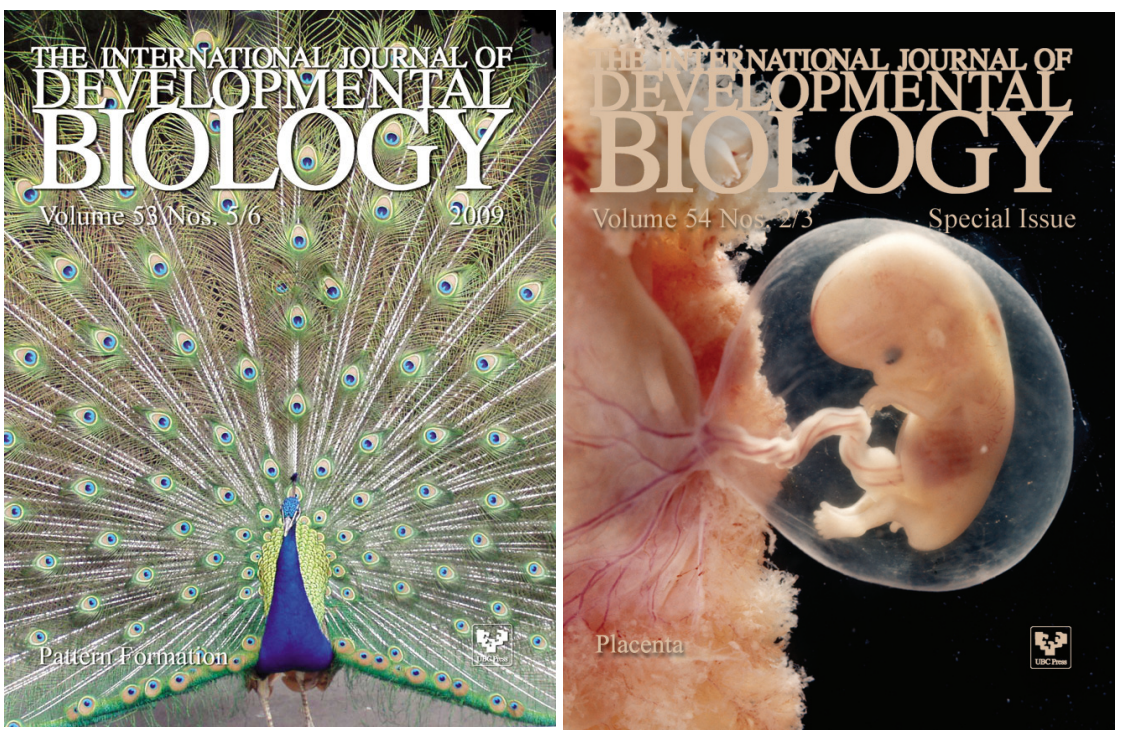

